\title{
A guide to clinical research supervision for psychiatrists: a mentoring approach
}

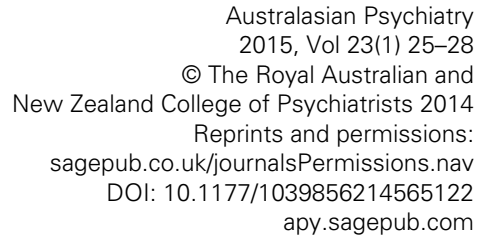
apy.sagepub.com

@SAGE

\begin{abstract}
Jeffrey C Looi Committee for Research, Royal Australian and New Zealand College of Psychiatrists (RANZCP), Melbourne, VIC, and; Academic Unit of Psychiatry and Addiction Medicine, Australian National University Medical School, Canberra, ACT, and; Mental Health Service, ACT Health Directorate, Canberra Hospital, Woden, ACT, Australia
\end{abstract}

Steve Kisely Committee for Research, RANZCP, Melbourne, VIC, and University of Queensland School of Medicine, Woollongabba, QLD, Australia

Matthew D Macfarlane Committee for Research, RANZCP, Melbourne, VIC, and; Graduate School of Medicine, University of Wollongong, Wollongong, NSW, and; Illawarra Shoalhaven Local Health District, Wollongong, NSW, Australia

Dan Siskind Committee for Research, RANZCP, Melbourne, VIC, and; School of Medicine and Metro South Addiction and Mental Health Service, University of Queensland, Brisbane, QLD, Australia

Geoff Smith Committee for Research, RANZCP, Melbourne, VIC, and; WA Centre for Mental Health Policy Research, School of Psychiatry and Clinical Neurosciences, University of Western Australia, Perth, WA, Australia

Stephen Macfarlane Committee for Research, RANZCP, Melbourne, VIC, and; Aged Psychiatry, Monash University, and; Caulfield Aged Psychiatry Service, Melbourne, VIC, Australia

\begin{abstract}
Objectives: To provide a guide for clinically-based psychiatrist supervisors of research projects for early career researchers.

Methods: This paper will describe a mentoring framework for supervision, for psychiatrist clinical research supervisors and early career researchers.

Results: The domains discussed include, across various aspects of a study: the role of the supervisor, project management, and where and when to seek advice.

Conclusions: Supervision of clinical research can be a professionally rewarding experience for psychiatrists, as well as early career researcher supervisees.
\end{abstract}

Keywords: clinical research, guidelines, mentoring, project management, psychiatrist, supervision

'One becomes a beginner after 1000 days of training and an expert after 10,000 days of practice' (Masutatsu Oyama).

Research experience is an important component of the Royal Australian and New Zealand College of Psychiatrists (RANZCP) training program. Most principal supervisors of research for early career researchers (such as the Scholarly Project) are likely to be clinical psychiatrists. Mentoring in clinical research supervision can be professionally rewarding for supervisor and supervisee, as can the excitement and sense of achievement of analysing data that the supervisee has diligently collected. This guide for supervisors should be read in conjunction with the complementary papers for early career researchers in this series, particularly those on framing a question, conducting research, analysing data and writing up papers.

\section{How and when to get started}

Once approached to supervise a project, the first step is to advise an early career researcher about the point at which their research project should be undertaken.

Considerations should include the supervisee's:

- $\quad$ Stage of career;

- Research skills and literacy;

Corresponding author:

Jeffrey Looi, Academic Unit of Psychiatry and Addiction Medicine, Australian National University Medical School, Building 4, Level 2, Canberra Hospital, PO Box 11, Woden, ACT 2605, Australia.

Email: jeffrey.looi@anu.edu.au 
- Time available, with respect to clinical duties; and

- Other competing commitments (non-clinical responsibilities).

If supervisees need to develop core research skills, such as information literacy and statistical and/or methodological skills, they can be taught by the supervisor, as well as encouraged to attend educational courses to supplement their learning. Time commitments need to be considered carefully, in view of the supervisee's clinical training and service requirements, and supervisees may benefit from advice in balancing commitments. Given the possible lead times involved in planning and executing a project, an earlier start is better. As the project may span a considerable length of time, having the same primary supervisor for the duration of the project is crucial. Help can be sought from co-supervisors, if available, upon loss of the primary supervisor due to unforeseen consequences.

\section{Supervisors and supervisees}

Supervisors should consider whether they have the skills, interest and availability to be the primary supervisor. Useful skills are a broad understanding of various research methodologies, including the knowledge of where, when needed, specialist research advice can be enlisted. Psychiatrists interested in supervising clinical research can link in with their local specialist training program or university Department of Psychiatry. In addition, if these psychiatrists are already conducting research, they can list this interest on their institutional website, including whether they are willing to supervise projects.

Agreeing to be a supervisor may relate to the fit with the supervisee's research interests and the compatibility of their personal and professional approaches (including sense of humour) with many potential supervisees actively seeking out supervisors they think will be compatible. Before a formal supervision process is undertaken, it is important to meet in person with the potential supervisee. Often, a potential supervisee and supervisor can agree to reciprocally assess suitability of working with each other on a time- and resource-limited pilot research project. Availability is important, as supervisees may need advice and support throughout their project, and sometimes with unforeseen urgency, e.g. unexpected ethics committee feedback.

From the supervisor's perspective, it can be professionally rewarding to supervise research, analogous to the role many clinical supervisors practise in the medical specialist apprenticeship model. Over and above the mentoring role, the supervisor can also learn new approaches, skills and ideas from the supervisee, as well as potentially collaborating on a published paper arising from the research. Enthusiastic supervisees can spur synergistic research and professional development.
Discussion of the mutual aims and purposes of supervision is important, to clarify expectations from each end, so these can be built into the setting of tasks and goals. Boundary issues are best discussed at the outset, in that a certain personal distance is required for a supervisor to retain an accurate perspective on advising on a supervisee's research project; and boundaries must be monitored by the supervisor on an ongoing basis, as the supervision evolves over time. ${ }^{1}$ As the supervisor is working in the role of mentor, it is incumbent on the supervisor to maintain appropriate professional boundaries, to allow the supervisee to develop their skills in a validating, non-exploitative working relationship.

The amount of guidance provided evolves with iterative development of the supervisee's skills with supervisor support. Giving and receiving feedback is crucial for supervisors and supervisees ${ }^{2}$ :

1. Feedback should be contemporaneous with the developmental task, or at the very least soon after the task;

2. The sandwich feedback method is useful (in part adapted here by the authors from sports coaching);

3. Begin feedback with reflecting on supervisee's strengths/skills and/or correct actions;

4. Explain where problems occurred for supervisee, provide constructive analysis, and if needed, model the correct actions/necessary skills, including nested observation and feedback, as supervisee practises under supervision; and

5. Motivationally summarise the above in the context of the supervisee's existing strengths and skills, along with encouragement to continue to practise, in order to improve.

Most universities also offer short courses on research supervision that may be helpful.

As in clinical supervision, demonstration and modelling may be needed in the beginning, together with observation and feedback to the supervisee, as they develop and practise skills. For example, the coding and analysis of data can be demonstrated by the supervisor, followed by asking the supervisee to attempt the analysis on their own, and then looking at the results together and giving feedback. Similarly, the supervisor can model for the supervisee how they search for information and advice, when they come upon a gap in the supervisor's knowledge. Tasks that stretch, and thus develop, the skills of the supervisee can be introduced with increasing independence levels. For example, supervisees can be coached on communication with collaborators, so that they learn how to manage this independently. Supervisees should be encouraged to deliberately practise and iteratively reflect on the skills developed, in order to improve their expertise. To support this developmental process, the supervisor should 
provide appropriate prompts and be available for discussion in person and via phone or email.

\section{Framing a question}

Supervisees may present with particular questions that the supervisor can, through discussion, help the supervisee refine, as well as enlist a specialist researcher co-supervisor, if needed. Alternatively, a supervisee may approach a supervisor seeking advice on a relevant topic, especially if the supervisor is engaged in research; or on the choice of a co-supervisor, whom may be conducting research in a particular area of interest. In other cases, the supervisee may be interested in enrolling in a formal research qualification, such as a Masters or Doctorate, by research and the supervisor may assist by brokering connections to a university academic department or other research institution. Due to both the limited time frame for training and competing commitments, a key role for the supervisor may be to gently keep the supervisee on track, to frame a question that can be reasonably investigated within the time available.

\section{Planning and designing a study}

The supervisor should guide the supervisee in choosing a suitable methodology for their project:

- A quality assurance project or clinical audit;

- A literature review;

- Empirical research (qualitative or quantitative);

- A case series; or

- An equivalent project (as approved by the Scholarly Project Subcommittee, if specifically targeted for the RANZCP Competency Based Fellowship Program).

The type of study is determined by the question, but also the broad context in which the supervisee is trying to conduct research. This is best illustrated by examples based on the above:

- A clinical audit may be of interest for those interested in quality and safety;

- A literature review may be the basis of an introductory chapter for a research thesis;

- Empirical research may be of interest, as part of a research thesis, and/or an opportunity to participate in an existing research project;

- A case series may be of interest, for those with particular clinical foci, but whom will still need to be rigorous in analysis and synthesis; and

- Judicious replication of previous research is also an important part of scientific progress, and it can inform further investigations.
It is also useful to consider a suitable back-up project related to the original proposal, in case of unforeseen problems.

\section{Conducting a study and project management}

Supervisors should help the supervisee set clear and realistic time-lines for each stage of the project. Factors to consider, and to make allowance for in supervision, include time involved in:

- Reviewing the literature;

- Ethics approval or exemption: this may be a challenging area for supervisees, due to research involving both the Health Service and academic institutional ethics committees, including their various informational requirements, and feedback and amendments as research progresses;

- Using the correct methodology for qualitative and quantitative studies;

- Consultation with consumers and/or carers;

- Sizing sample populations appropriately;

- Power calculation, for clinical recruitment studies;

- Coding and analysis of qualitative data;

- Protecting confidentiality and privacy considerations;

- Collecting data;

- Controlling the quality of data;

- Analysing with the proposed statistics and methodology;

- Applying for funding;

- Interpreting results; and

- Writing various sections of a paper.

Project management and general supervision are best underpinned by regular supervision sessions, scheduled perhaps weekly initially, and then spaced, but still regularly thereafter. If a co-supervisor is involved, the supervisee may meet separately with the co-supervisor regularly, but there will still need to be regular meetings with all supervisors and the supervisee at agreed intervals. Also, the supervisors should contact each other as needed, including the supervisee in the discussion whenever possible. Regular supervision sessions should cover:

- Progress to date toward goals;

- Problems experienced or anticipated;

- Seeking advice, as needed (expert/co-supervisor);

- Recalibration or confirmation of time-lines; 
- Planning the next goals; and

- Planning the next meeting.

Some truisms in clinical research project management are: unexpected events will happen, including roadblocks at each of the above stages; consequently, conduct of the research takes longer than expected and not as much usable data is obtained as was originally planned; data analysis requires adjustment and time, on account of the former truisms; it takes a considerable time to interpret results; and following all of the above, there is still the write-up.

\section{Completing and submitting the project}

Supervisors should guide supervisees to maintain a suitable work-plan and time-line, to complete and submit the project by an agreed due date. Probably the best advice is to encourage the supervisee to write up the project in a step-wise manner, for any type of study, so as to avoid writer's block at the last stage. Asking the supervisee to write an abstract before the paper is written in full can help frame the tasks in each section of the paper. In the case of a quantitative scientific project and paper, the introduction, hypotheses and methods can be written as the supervisee is collecting data, or indeed prior to the ethics submission.

The final draft of the paper should be carefully reviewed by all the supervisors, with sufficient time for feedback and revisions. It can be useful, with the agreement of the supervisee, to seek an external reviewer familiar with the research field, to provide additional feedback, which the supervisors can guide the supervisee in incorporating. If the paper is submitted for publication, reviewers may also give feedback that can be incorporated into the write-up.

'Seven times down, eight times up' (Japanese Proverb).

\section{Troubleshooting}

Problems may arise with the conduct of the project, within supervision and with the supervisee. Supervisors should address any problems with the project by meeting directly with their supervisees.

Expert advice may need to be sought regarding technical research matters, such as ethics requirements, methodology and statistical analysis. The supervisor should encourage the supervisee to persevere through the challenges of a research project; this may involve, within appropriate boundaries, self-disclosure by the supervisor of how that supervisor personally dealt with challenges that they had experienced in conducting clinical research, especially as a spur to reflection and discussion. Through modelling, encouragement of practice and feedback, the supervisor can help the supervisee build resourcefulness and resilience.

If there is a problem with supervision arising from interpersonal difficulties between the primary supervisor and supervisee, the relevant Director of Postgraduate Studies (or Training) and co-supervisors, if involved, should be consulted so that remedial action may be taken. If supervisor-supervisee interpersonal problems cannot be resolved with intervention, a new supervisor should be appointed.

When a supervisee is experiencing personal problems, collegial support should be provided, along with encouragement to seek professional psychological support, as required.

\section{Conclusions}

Mentoring supervision of a research project can be immensely rewarding for clinical psychiatrist supervisors and their supervisees. There are opportunities for mutual encouragement and learning, engagement in medical research, potential scientific publication and the supervisees learning how to supervise others, in the future. The skills deliberately developed in clinical research can be foundational for a lifetime of continuously-improving skilled clinical practice.

'When the student is ready, the master will appear' (Japanese Proverb).

\section{Disclosure}

The authors report no conflict of interest. The authors alone are responsible for the content and writing of the paper.

\section{Note}

Useful references include the RANZCP website on research: www.ranzcp.org/Publications/ Research/Research-in-Psychiatry.aspx

\section{References}

1. Johnson B and Ridley C. Elements of mentoring. New York: Palgrave Macmillan, 2008.

2. Chur-Hansen A and McLean S. On being a supervisor: The importance of feedback and how to give it. Australas Psychiatry 2006; 14: 67-71. 